\title{
The Relationship between Students' Satisfaction in the LMS "Acadox" and Their Perceptions of Its Usefulness, and Ease of Use
}

\author{
Nahed F. Abdel-Maksoud ${ }^{1 \& 2}$ \\ ${ }^{1}$ Arab East College for Graduate Studies, Riyadh, Saudi Arabia \\ ${ }^{2}$ College of Education, Damietta University, Egypt \\ Correspondence: Nahed F. Abdel-Maksoud, Arab East College for Graduate Studies, Riyadh, Saudi Arabia. \\ E-mail: nahedfahmy88@yahoo.com
}

Received: December 1, 2017

Accepted: December 19, 2017

Online Published: January 16, 2018

doi:10.5539/jel.v7n2p184

URL: http://doi.org/10.5539/jel.v7n2p184

\begin{abstract}
This study examined the relationship between students' satisfaction in the newly developed Learning Management System "Acadox", and their perceptions of its usefulness, and ease of use. The study used a descriptive correlational design to examine the relationships among variables, as they exist in their natural settings. To measure students' satisfaction in Acadox, perceptions of usefulness, and perceptions of ease of use of Acadox, a web-basecd survey was developed be the researcher. Data were collected from seventy-five students enrolled in courses that used Acadox as a learning management system in the Middle East region, namely, Egypt and Saudi Arabia. The findings of this study revealed that students' perceptions of ease of use, and perceptions of usefulness were significant predictors of satisfaction in Acadox. The findings of this study are consistent with the Technology Acceptance Model (TAM), which indicates that one's perceptions of ease of use, and perceptions of usefulness of the new technology are the key factors that determine whether user will accept or not the new technology.
\end{abstract}

Keywords: Acadox, LMS, TAM, perceived ease of use, perceived usefulness

\section{Introduction}

In E-learning contexts, there is a growing demand for the adoption of learning management systems (LMS). However, little research is done to investigate the factors affecting its usage. To fill this research gap, the Technology Acceptance Model (TAM) was used to analyze the relationship between students' perceptions of the newly developed LMS Acadox, and perceived ease of use, and perceived usefulness.

\section{Significance of the Study}

There are many reasons why this study is important. First, up to the knowledge of the reasearcher, there are not any previous studies conducted on Acadox. Second, because end users' perceptions of technology are the most important part of technology use, understanding end users' perceptions allows better understanding of their technology use. Third, by understanding how end users perceive technology in terms of its usefulness, and ease of use, institutions can better implement their technology. Finally, by understanding end users' perceptions of technologies, companies that make and support technology can have a better understanding of whom and what they are dealing with. The process of understanding end users perceptions should be continual, to provide data on technology acceptance and use.

\section{Literature Review}

\subsection{Acadox}

According to Acadox website (2017), Acadox is considered one of the next generation learning management \& intelligent platforms. It is a social learning and academic networking platform. It provides an integrated package to help students manage their activities in a more efficient and organized way. Acadox is focusing on the MENA region and is solving the language barrier problem of many other systems by providing a fully Arabized interface. Acadox also provides more than learning management; it is completely cloud based which makes it flexible, and easily accessible from anywhere. Acadox also enables communication channels beyond one's college, which encourages knowledge sharing and collaboration. 


\subsection{Learning Management Systems}

According to McGill \& Klobas (2009), one of the most significant developments in the use of information technology (IT) in universities in the last decade has been the adoption of learning management systems to support the teaching and learning process. Learning management systems (LMS) are commonly used by higher education institutions to deliver, manage, and track online learning, as well as to facilitate communication and collaboration between instructors and students (Motaghian, Hassanzadeh, \& Moghadam, 2013). Ellis (2009) defines a learning management system as any software/hardware application that has the following functions: administration, tracking, documentation, and reporting for instructional/educational programs. The term "Learning Management System" can also be defined as an online learning platform, or software that is designed to organize and manage electronic learning (Anderson, 2008). The term "electronic learning" is used to express the use of internet to access learning content and resources, interacting with instructors and other students (Moore, Dickson-Deane \&, Galyen, 2011).

\subsection{Technology Acceptance Model (TAM)}

The theoretical framework that guides this study is based on the Technology Acceptance Model (TAM), introduced by Davis, Bagozzi, \& Warshaw (1989). This model tries to understand the factors that influence users' satisfaction in the new technologies. "TAM has become well-established as a robust, powerful and parsimonious model for predicting user acceptance" (Venkatesh \& Davis, 2000, p. 187). TAM has received wide attention from IT researchers for two reasons. First, it has a strong foundation in theory; Venkatesh \& Davis (2000) stated, "Substantial theoretical and empirical support has accumulated in favor of the technology Acceptance Model" (p. 186). Second, it can be used as a guideline to develop successful IT applications.

The technology acceptance model uses individual beliefs toward usefulness and ease of use to determine attitudes and intentions toward using new technological systems (Shin, 2009). According to TAM, the key predictors of individuals' acceptance and intention to use the new technology are their perceptions of its usefulness, and their perceptions of its ease of use (Davis, 1993). This model has its foundation in the theory of reasoned action developed by Martin Fishbein in 1975 and continued by Icek Aizen in 1980. Central to this theory is the idea that decisions come from analysis of end users' available information and their intentions to make rational choices.

Critical to the technology acceptance model is perception as the center of analysis. The technology acceptance model looks at two factors affecting an Individual's behavior when presented with new technology: perceived usefulness and perceived ease of use. Davis (1989) defines perceived usefulness as the degree to which a person sees that a certain system will boost his or her performance. In the context of E-Learning, (Sun, Tsai, Finger, Chen, \& Yeh (2008) define perceived usefulness as the degree to which user sees that the adoption of e-learning system can result in improving his or her learning outcomes. Perceived usefulness looks at end users' beliefs that using any particular technology will improve their individual performance.

As for perceived ease of use, it is defined by Davis (1989) as the degree to which a person believes that using a particular system is free of physical and mental effort. According to Davis, when a user perceives a system as easy to use, s/he is more likely to continue using that system. In the context of E-learning, perceived ease of use looks at end users' beliefs that a particular technology does not require effort (Sun et al., 2008). In perceived ease of use, there is more focus on actual technology. End users inquire how difficult technology will be to use in the process of completing their work assignments. Both types of perceptions will determine whether end users will accept and continue to use new technology or not.

\section{Research Questions}

To evaluate the newly developed LMS Acadox, we need to investigate students' perceptions of its usefulness and ease of use. Besides, satisfaction is critical in adopting new systems or new technologies. According to Al-Busaidi \& Al-Shihi (2011), users' satisfaction is very important because it determines whether they are going to continue using the system or not. Besides, we need to investigate whether or not perceptions of usefulness and perceptions of ease of use can be significant predictors of satisfaction in Acadox.

The main research question of this study is:

Are students' perceptions of Acadox usefulness and ease of use significant predictors of students' satisfaction in Acadox? 


\section{Method}

This study used a descriptive correlational design to examine the relationships among students' satisfaction in Acadox, and their perceptions of its usefulness, and ease of use, as they exist in their natural settings. The study used the survey research method to collect data, as it is best suited for studies that describe the characteristics of a population, including attitudes and orientations (Babbie, 1989). Data were collected using a web-based survey. Correlations and Regression analysis were conducted to determine whether the independent variables, perceived usefulness and perceived ease of use, are significant predictors of the dependent variable, students' satisfaction in Acadox.

\subsection{Participants}

Participants for the present study were 75 students from the Middle East region, namely, Egypt and Saudi Arabia, enrolled in courses that use Acadox as a learning management system. Thirty participants (40\%) were males, whereas forty-five $(60 \%)$ of them were females.

\subsection{Instrumentation}

A web-based survey was developed to measure students' satisfaction in Acadox, students' perceptions of the usefulness of Acadox, and students' perceptions of Acadox ease of use. Survey items were developed in relation to the study constructs and were based on the original Technology Acceptance Model questionnaire (Davis, 1989). The survey consisted of three main sections: section 1 measures satisfaction in Acadox, section two measures students' perceptions of the usefulness of Acadox, and section three measures students' perception of the ease of use of Acadox. Items were measured using a Likert 5-point scale ranging from 1 (strongly disagree) to 5 (strongly agree). The final version of the survey (see Appendix B) is a 42-question, self report instrument that takes approximately 10 minutes to complete.

The survey utilized a standard close-ended question and statement format with a 5-point Likert scale, ranging from Strongly Disagree to Strongly Agree. Acquiescence responses were controlled for in the survey by listing some items negatively and others positively (Mueller, 1986). Items number 2, 4, 6, and 11 were negatively phrased; and the coding for these items was reversed prior to analysis. Questions on the instrument were listed in the following sections:

- $\quad$ Section I: Satisfaction in Acadox (Q1-Q13)

- $\quad$ Section 2: Perceived Usefulness of Acadox (Q14-Q20)

- $\quad$ Section 3: Perceived Ease of Use (Q21-Q26)

\subsection{Instrumentation Validity}

A pilot test of the survey was conducted prior to its administration and validity was assessed. A panel of three experts who are all faculty members in Arab universities were asked to fill in a rubric to assess clarity, wordiness, balance, and relationship to the problem. Based on feedback and responses from the validity panel, revisions to the instrument were made.

\subsection{Instrumentation Reliability}

Reliability was tested twice using Cronbach coefficient alpha, once during the pilot test and again after collecting the data for the present study. Cronbach coefficient alpha for the instrument was 0.874 . According to Mueller (1986), a well-constructed scale should have a reliability coefficient of 0.80 or higher. Since the calculated Cronbach coefficient alpha calculated for the scale used in this study was greater than 0.80 , it is considered reliable.

\section{Results}

To measure students' satisfaction in Acadox, the means and standard deviations of the first thirteen items of the survey (Section 1), were calculated. Table 1, shows the mean and standard deviation of each item in section 1 . 
Table 1. Students' satisfaction in Acadox

\begin{tabular}{llll}
\hline $\mathrm{N}$ & Phrase & Mean & Std. Deviation \\
\hline 1 & The material I learned through Acadox was valuable to me. & 4.32 & 0.68102 \\
2 & The discussion part of this course was ineffective. & 2.3067 & 1.10250 \\
3 & Learning through Acadox has increased my knowledge of the content. & 4.5333 & 0.64375 \\
4 & I really feel that I am wasting my time using Acadox. & 1.5867 & 0.83978 \\
5 & I feel positive about Acadox as a whole. & 4.3733 & 0.67330 \\
6 & I was rarely happy with the quality of learning through Acadox. & 2.0267 & 1.07770 \\
7 & I did not have problems using Acadox to access course materials. & 4.333 & 0.70391 \\
8 & Learning through Acadox is enjoyable. & 4.3600 & 0.67062 \\
9 & I would recommend using Acadox to others. & 4.6000 & 0.61512 \\
10 & Overall, I am satisfied with learning through Acadox. & 4.6000 & 0.61512 \\
11 & To be honest, I do not see any reason for learning via Acadox. & 1.5467 & 1.00396 \\
12 & I am very satisfied with the services provided by Acadox. & 4.4400 & 0.64179 \\
13 & I intend to continue using Acadox in the future. & 4.4267 & 0.75647 \\
\hline Mean of Satisfaction & 3.6503 & 0.771157 \\
\hline
\end{tabular}

As shown in Table 1, students overall mean satisfaction was 3.6503, which means that students were overall satisfied in Acadox.

\subsection{Students' Perceptions of Acadox Usefulness}

To measure students' perceptions of the usefulness of Acadox, the means and standard deviations of the items in the second section of the survey (Section 2) were calculated. Table 2 shows the means and standard deviations of each item in section 2 .

Table 2. Students' perceptions of Acadox usefulness

\begin{tabular}{llll}
\hline $\mathrm{N}$ & Phrase & Mean & Std. Deviation \\
\hline 14 & Using Acadox helped me broaden my knowledge in course topics. & 4.5067 & 0.64459 \\
15 & Using Acadox helped me improve my competencies in my specialization. & 4.2533 & 0.69929 \\
16 & Learning via Acadox improved my skills in using online platforms. & 4.5467 & 0.57641 \\
17 & Using Acadox makes me more productive student. & 3.9600 & 0.82920 \\
18 & Overall, I find using Acadox to be useful. & 4.7867 & 0.44398 \\
19 & Acadox helps me accomplish my tasks more quickly. & 3.9600 & 0.92181 \\
20 & The quality of tasks I accomplish increased after using Acadox. & 3.9867 & 0.89281 \\
\hline Mean of perceived usefulness & 4.2857 & 0.71544 \\
\hline
\end{tabular}

As shown in Table 2, mean of students' perceptions of the usefulness of Acadox was 4.2857, which means that students highly perceived Acadox to be useful.

\subsection{Students' Perceptions of Acadox Ease of Use}

To measure students' perceptions of the ease of use of Acadox, the means and standard deviation of the items in the third section of the survey (Section 3) were calculated. Table 3 shows the means and standard deviations of each item in section 3 .

Table 3. Students' perceptions of Acadox ease of use

\begin{tabular}{llll}
\hline N & Phrase & Mean & Std. Deviation \\
\hline 21 & Acadox layout is user-friendly. & 4.5467 & 0.57641 \\
22 & I do not have any problems using Acadox. & 4.1600 & 0.78912 \\
23 & Acadox layout is in good structure. & 4.6400 & 0.53625 \\
24 & The layout design of Acadox makes it easy to read and navigate. & 4.7067 & 0.51395 \\
25 & Overall, Acadox user-interface design is satisfactory. & 4.7600 & 0.48879 \\
26 & Acadox is an easy to use learning platform. & 4.7867 & 0.47344 \\
\hline \multicolumn{2}{l}{ Mean of perceived ease of use } & 4.6000 & 0.56299 \\
\hline
\end{tabular}

As shown in Table 3, mean of students' perceptions of the ease of use of Acadox was 4.6000, which means that students highly perceived Acadox to be useful. 


\subsection{The Relationship between Students' Satisfaction in Acadox and Their Perceptions of Its Ease of Use}

To calculate the relationship between students' satisfaction with Acadox on the one hand and their perceptions of its ease of use, Pearson Correlation was calculated, as shown in Table 4.

Table 4. The relationship between students' satisfaction and perceptions of ease of use

\begin{tabular}{llll}
\hline & & Satisfaction & Perceived ease of use \\
\hline Satisfaction & Pearson Correlation & 1 & $0.608^{* *}$ \\
& Sig. (2-tailed) & & 0.000 \\
& $\mathrm{~N}$ & 75 & 75 \\
\hline Perceived ease of use & Pearson Correlation & $0.608^{* *}$ & 1 \\
& Sig. (2-tailed) & 0.000 & \\
& $\mathrm{~N}$ & 75 & 75 \\
\hline
\end{tabular}

As shown in Table 4, the value of $r$ was $0.608^{* *}$, which is significant at the $(0.000)$, which indicates that there is a positive relationship between students' satisfaction in Acadox, and their perceptions on its ease of use. The more students perceive Acadox to be easy to use, the more they are satisfied in it.

\subsection{The Relationship between Students' Satisfaction in Acadox and Their Perceptions of Its Usefulness}

To calculate the relationship between students' satisfaction in Acadox on the one hand and their perceptions of its usefulness, Pearson Correlation was calculated, as shown in Table 5.

Table 5. The relationship between students' satisfaction and perceptions of its usefulness

\begin{tabular}{llll}
\hline & & Satisfaction & Perceived Usefulness \\
\hline Satisfaction & Pearson Correlation & 1 & $0.564^{* *}$ \\
& Sig. (2-tailed) & & 0.000 \\
& N & 75 & 75 \\
\hline Perceived Usefulness & Pearson Correlation & $0.564^{* *}$ & 1 \\
& Sig. (2-tailed) & 0.000 & \\
& N & 75 & 75 \\
\hline
\end{tabular}

As shown in Table 5, the value of $r$ was $0.564 * *$, which is significant at the $(0.000)$. This indicates that there is a positive relationship between students' satisfaction in Acadox, and their perceptions of its usefulness. The more students perceive Acadox to be useful, the more they are satisfied with it.

To answer the main research question: "Are students' perceptions of Acadox usefulness and ease of use significant predictors of students' satisfaction in Acadox?"

Multiple regression analysis was run with the two predictors; perceptions of usefulness, and perceptions of ease of use. Though the sample of this study was a convenient, not a random sample, and one assumption of the regression analysis is that there is randomness in each case. However, regression analysis is generally robust to violation of this assumption (Green \& Salkind, 2005). Table 6 shows the relationship between perceptions of usefulness, perceptions of ease of use as predictors of satisfaction in Acadox.

Table 6. Perceptions of usefulness and perceptions of ease of use as predictors of satisfaction in acadox

\begin{tabular}{llllll}
\hline Source & Type III Sum of Squares & df & Mean Square & F & Sig. \\
\hline Corrected Model & 35.510 & 2 & 17.755 & 93.826 & .000 \\
Intercept & 3935.931 & 1 & 3935.931 & 20799.570 & .000 \\
Variables & 35.510 & 2 & 17.755 & 93.826 & .000 \\
Error & 42.009 & 222 & .189 & & \\
Total & 4013.450 & 225 & & & \\
Corrected Total & 77.519 & 224 & & & \\
\hline
\end{tabular}

As shown in Table $6, F=93.826, p<.001$. This means that the two variables, perceptions of usefulness, and perceptions of ease of use are significant predictors of students' satisfaction in Acadox. This result suggests that 
students who perceive Acadox to be useful, and easy to use, tend to be more satisfied in Acadox. An examination of the contribution of each of the two predictors revealed that perceptions of ease of use, was more important than the other predictor, perceived usefulness, because it had more part correlation with the dependent variable, satisfaction in Acadox. This suggests that perceived ease of use accounts for a more significant amount of variation in the dependent variable, satisfaction in Acadox. The more students perceived Acadox to be easy to use, the more they are satisfied in Acadox.

\section{Discussion}

Using the Technology Acceptance Model as a framework, this correlational study tries to find out if there is a relationship between students' satisfaction in the newly developed learning management system Acadox and its perceived ease of use, and perceived usefulness. Because there is very little research conducted within this type of LMS, this study tries to provide some insights into users' acceptance or satisfaction in that new system. Because perceived usefulness and perceived ease of use are critical in determining users' intention to continue using new technology, this study focuses on how students perceive Acadox in the light of its usefulness and ease of use.

This study revealed that perceived ease of use, and perceived usefulness of Acadox are significant predictors of satisfaction in it. Both types of perceptions, perceived ease of use, and perceived usefulness correlated with students' satisfaction in the new learning management system, However, of the two perceptions, ease of use was more important as reflected by the $r$-value $\left(0.608^{* *}\right)$. This means that user friendliness, or ease of use of new technology is the more important determinant of the acceptance of this new technology, which stresses the need to design technologies that are user friendly, and that don not require any physical or mental effort on the part of users. The findings of the study corresponds with the principles of the Technology Acceptance Model; when a user perceives a system as useful, and easy to use, s/he is more likely to accept or be satisfied with that system. The implications of these findings are that new technologies should be designed with these two principles in mind: perceived ease of use, and perceived usefulness. Evaluating existing systems in the light of these two principles can improve the design and implementation of such systems. Further research is required to evaluate this new learning management system, and compare it to other existing learning management systems.

\section{Delimitations of the Study}

This study focused on the perceptions of usefulness and perceptions of ease of use as it pertains to Acadox. Participants in this study were undergraduate students enrolled in courses that used Acadox as a learning management system in two countries in the Middle East region during the year 2017. Further testing using other populations would be necessary to confirm whether the relationships reported here are similar in other populations and under other conditions. In this study, data were collected using the survey research method. Therefore, all predictors and the criterion variable of student satisfaction in Acadox were subjective and self-reported by the participants. Future studies may consider using other methods such as quasi-experimental designs to confirm the findings of this study.

\section{References}

Acadox. (2017). Retrieved from http://acadox.com

Al-Busaidi, K., \& Al-Shihi, H. (2011). Key factors to instructors' satisfaction of learning management systems in blended learning. Journal of Computing In Higher Education, 24(1), 18-39. https://doi.org/10.1007/s12528-011-9051-x

Anderson, T. (2008). The theory and practice of online learning. Edmonton: AU Press.

Babbie, E. (1989). The practice of social research (5th ed.). Belmont, CA: Wadsworth Publishers.

Davis, F. (1993). User acceptance of information technology: system characteristics, user perceptions and behavioral impacts. International Journal of Man-Machine Studies, 38(3), 475-487. https://doi.org/10.1006/imms.1993.1022

Davis, F., Bagozzi, R., \& Warshaw, P. (1989). User Acceptance of Computer Technology: A Comparison of Two Theoretical Models. Management Science, 35(8), 982-1003. https://doi.org/10.1287/mnsc.35.8.982

Ellis, R. K. (2009). Learning Management Systems. Td.org. Retrieved from https://www.td.org/Publications/Newsletters/Learning-Circuits/Learning-Circuits-Archives/2009/09/Learni ng-Management-Systems-2009

Green, S. B., \& Salkind, N. J. (2005). Using SPSS for Windows: Analyzing and understanding data (4th ed.). Upper Saddle River: Prentice-Hall. 
McGill, T., \& Klobas, J. (2009). A task-technology fit view of learning management system impact. Computers \& Education, 52(2), 496-508. http://dx.doi.org/10.1016/j.compedu.2008.10.002

Moore, J., Dickson-Deane, C., \& Galyen, K. (2011). E-Learning, online learning and distance learning environments: Are they the same? The Internet and Higher Education, 14(2), 129-135. https://doi.org/10.1016/j.iheduc.2010.10.001

Motaghian, H., Hassanzadeh, A., \& Moghadam, D. (2013). Factors affecting university instructors' adoption of web-based learning systems: Case study of Iran. Computers \& Education, 61, 158-167. https://doi.org/10.1016/j.compedu.2012.09.016

Mueller, D. J. (1986). Measuring social attitudes: A handbook for researchers and practitioners. New York: Teachers College Press.

Shin, D. (2009). An empirical investigation of a modified technology acceptance model of IPTV. Behaviour \& Information Technology, 28(4), 361-372. https://doi.org/10.1080/01449290701814232

Sun, P., Tsai, R., Finger, G., Chen, Y., \& Yeh, D. (2008). What drives a successful E-Learning? An empirical investigation of the critical factors influencing learner satisfaction. Computers \& Education, 50(4), 1183-1202. https://doi.org /10.1016/j.compedu.2006.11.007

Venkatesh, V., \& Davis, F. (2000). A Theoretical Extension of the Technology Acceptance Model: Four Longitudinal Field Studies. Management $\quad$ Science, 466 46-204. https://doi.org/10.1287/mnsc.46.2.186.11926

\section{Copyrights}

Copyright for this article is retained by the author(s), with first publication rights granted to the journal.

This is an open-access article distributed under the terms and conditions of the Creative Commons Attribution license (http://creativecommons.org/licenses/by/4.0/). 